\title{
Slowing down with tourism
}

\section{Johan:}

The Call for Papers to this Special Issue was published in early April, as the whole world was still hesitantly cancelling and postponing events planned for the year with the COVID-19 pandemic in its initial global reach. We have since seen a glut of papers and special issues that have been published in the past half year, during which we have been "slowing down" as well as "speeding up" in different ways in our academic lives. The original CfP highlighted the earth's environmental crisis as a first matter, and it looked at COVID-19 as a potential for reduced global mobility and consumption. Now, as the people around the world starts to realise that we will be living WITH the virus still for years to come, rather than imagining a sudden end to it as the initial predictions forecasted, we stand on the cusp of new scenarios. Global mobility has indeed been dramatically reduced, but new types of mobility have also emerged. After the initial reduction in consumption, due to total closedowns of manufacturing and transport infrastructure, a new boom of different consumption related to home schooling and offices, gardening and outdoor recreation have emerged.

Jennie:

When we proposed the theme of "slowing down with tourism" earlier this year, we were just beginning to sense the spatiotemporal shifts brought on by the pandemic. Life for those of us lucky enough to be able to work from home was simultaneously speeding up and slowing down, as Johan notes. New temporal landscapes were emerging, ones marked by urgency and monotony, by zoom invites, time zone calculators, and "What day is it, again?," by pressing responsibilities, antsy toddlers, bored teenagers, and corporate requests for our patience with the inevitable delays due to COVID-19.Time is not simply marching on; it is layering in on itself and pooling up.

As scholars and teachers of tourism, we have been intrigued by the possibility of doing things differently and at a different pace. Like Gunnar and Johan describe below, my students and I had to get up to speed with new online platforms. I had to revise syllabi to capture the timeliness of the moment. And yet I felt my teaching and scholarship slowing down. Teaching tourism has certainly posed new opportunities, such as Outi's embrace of teaching outdoors or, in my case, incorporating projects on virtual tourism and staycations while we followed the virus's brutal itinerary from one destination to the next. In many special issues like this one, and in webinars and zoom conferences, tourism scholars have amplified our field's longstanding 
calls for more just and sustainable tourism practices. Could the shock of the pandemic be just what the world needs to downshift tourism into a more sustainable gear?

Summary of the first research note in this issue:

In her research note, Tarja Salmela conducts speculative fabulation about future tourism, suggesting that post-pandemic tourism holds a possibility for new type of responsibility in a form of post-anthropocentric tourism. Post-anthropocentric tourism is needed because of the imprint that tourism is having on our planet, and due to the lack of long-term visions within the industry. Salmela shows how post-anthropocentric tourism requires stepping forward from the anthropocentric ethics, towards new types of tourism worlds. Through speculative fabulation, she draws a picture of imaginary village called Pirpola, where tourism has turned into visiting. Here visiting represents an alternative form of tourism, which is based on collective action and care.

\section{Gunnar:}

For many, the situation has brough a complete conflation of workplace and home that has meant increased efficiency and gaining of time for some while for others increasing stress, frustration and loneliness. On a general level people seem to be making more out of their immediate surroundings for recreation and leisure. Some kind of proximity tourism seems to be on the rise. In some sense the COVID-19 has presented an opportunity to rethink and (re)discover activities and leisure/travel possibilities domestically. In Iceland, there was actually an increase in tourism in the regions usually on the periphery on tourist's itineraries this summer and many companies have started to take notice and alter their offer so it better fits local and domestic demands. It is probably too early to say if this change can be interpreted as a step towards post-anthropocentric tourism along the lines Tarja Salmela discusses in her contribution, but one can be hopeful that at least certain possibilities or openings towards more responsible tourism have emerged. Johan:

Salmela's research note is a brave undertaking; fantasy is a powerful tool, and it is interesting how it is always shaped within the confines of existence. What does it say about humans' psyche when the majority of science fiction tales are dystopias, and only a tiny fraction are utopias? Are we all too focused on the downside, so that we cannot even fantasise about a better future? There's been talk on TRINET (Tourism Research Information Network) about the record number of article submissions, i.e., many academics can now focus on getting stuff off their desks, off their minds that have been held back by other running commitments before. At the same time, academics with children have during lockdowns and separation from family networks been forced to adapt their lives to home schooling, home care, and associated new tasks that the closure of clubs and care has meant.

Simultaneously, many have had to adapt (in some cases for the first time in their lives) teaching in a virtual environment. Learning new software, skills, procedures, pedagogic styles, assignments - a whole raft of new information. This has for some been a boost of morale, for others a negative feature which students have to endure. 
Outi:

Sketching the Call for Papers to this Special Issue in March led to an inspiring discussion among the editorial board members. I still have the email thread saved, in which Emily Höckert suggested that texts submitted to the Special Issue could be like 'singing from our balconies' - reaching for others in times of social distancing. I tested this autumn teaching outdoors - even more than what I have done previously. The outdoor sessions worked in a way as a form of reaching for others in a situation where we were longing for physical interaction. The outdoor sessions also brought a new rhythm to the teaching. Students slowed down to the discussions in a different way than what they do in the classroom. Therefore, I would say that the situation has helped us to turn towards virtual environments and towards our online communities, but also towards outdoors. In teaching, but also during our leisure time.

Summary of the second research note in this issue:

In the second research note - a conversation paper - Kati Pitkänen, Olga Hannonen, Stefania Toso, Nick Gallent, Iqbal Hamiduddin, Greg Halseth, C. Michael Hall, Dieter K. Müller, Andrey Treivish, and Tatiana Nefedova take the reader on a tour through the second home landscape during the COVID-19 pandemic in Italy, UK, Canada, New Zealand and Australia, Nordic countries and Russia. The tour reveals that although second home cultures and contexts differ globally, people have looked for safety at the second homes during the pandemic all over the world. The authors claim that acting as a sanctuary is not a new role for second homes, since the rich urban elites have always fled to their country estates for safety during times of upheavals and pandemics. At the same time there has been fears of urban dwellers spreading the virus to rural areas and exceeding the limits of the local health care capacity. Hence, many countries have imposed recommendations to stay away. After removing restrictions, second home sales and rentals have peaked.

Johan:

There has been no (or very little) travelling going on, people have had an upsurge of virtual conferences, meetings and teaching - and the general ebb and flow of sentiments about when we can start imagining a "post" time is still going on. What all of this has meant in practice is that we might have slowed down from rushing from place to place (a physical slow down) but have at the same time been able to and needed to speed up (on an intellectual level). I have read about similar trends to what Pitkänen et al report in the second research note here in Japan, with second home sales and rentals booming. However, there has also been decidedly unhospitable moves like regional towns actively rejecting outsiders with notices in restaurant windows that they don't serve anybody from outside that prefecture.

Summary of the third research note in this issue:

Henna Konu and Liisa Tyrväinen explore in their research note how trading landscape and recreational values of tourism environments could enhance the sustainable tourism development. The COVID-19 pandemic has increased interest towards nature-based tourism and led to increase in number of visitors in different nature areas. In Finland, nature-based tourism and recreation takes place both in protected areas and in privately owned forests, and still the sustainable use of nature in the context of tourism has most often been studied in regard to the protected 
areas. Because there does not exists currently incentives for landowners to protect landscapes and recreational values, Konu and Tyrväinen introduce a model developed in Ruka-Kuusamo area, in Finland. Through the new model, the landowners will receive compensation for protecting the landscape, which will furthermore enhance the ecological sustainability of the area.

\section{Gunnar:}

I can relate to what Johan and Outi describe. The COVID-19 and all what it has entailed for re-ordering of our lives has meant change of rhythm and pace. While academic travelling, be it for conferencing or fieldwork has to a great extent been halted, the pace of other activities has changed, and some are seemingly moving faster still. For instance, on-line meetings have proliferated and many experience that via tools like Zoom and Teams it is possible to squeeze more meetings into the daily schedule than ever before. While this may be positive for management many feel 'zoombified'. Also, new (for many) practices of teaching alter the pace of co-creating knowledge with students and demand that teachers and students learn fast in using different kinds of platforms and techniques. It may however also create opportunities of slowing down and do scholarship in different ways and find "a slower way of scholarly being" (Ulmer, 2017, p. 202, original italics). As Outi mentions, the situation may open up possibilities to move teaching outside, thus, to situate the issues and questions being dealt with in different ways, and to make use of virtual learning environments to create quieter and more peaceful spaces for group work and dialogue albeit they may lack the spontaneity of face-to-face communication.

Summary of the fourth research note in this issue:

In her research note, Milla Uustalo discusses how the policymakers in a small Finnish municipality see tourism development and planning. According to Uusitalo, the policymakers justify the lack of enhancement of tourism development with the limited economic resources available and with the formal responsibilities of the municipalities. The municipalities are not formally responsible to enhance tourism development. However, municipalities are responsible for developing possibilities for entrepreneurial activities. Uustalo suggests that in order to overcome the impacts of COVID-19 pandemic the municipalities should take stronger role in planning tourism and preparing for unexpected situations.

Jennie:

Daily, weekly, and seasonal rhythms are not unfolding, but rather seem to be orbiting around my house, my desk, my favorite hiking routes, and my computer. As Outi and Gunnar have noticed in their own locales, people are already turning to nearby and nature-based recreation. I have seen this, too, in Taos, where I am weathering the pandemic with my family. Our limited social lives are conducted almost entirely outside on socially distanced hikes with friends. This small town in the high desert area of northern New Mexico has also become a second-home haven, with many of the newcomers fleeing from the wildfires and surging COVID-19 cases in neighboring states. Climate catastrophe and the virus appear to be comorbidities.

Nevertheless, I echo Gunnar's cautious optimism that the pandemic might open more possibilities for sustainable tourism. Perhaps tourism mobilities, like time, might pool up and slow down rather than continue their onward, outward, and extractive expansion. The contributions in this special issue focus our attention on what this might look like, whether in the form of sec- 
ond-home tourism, nature-based tourism, or practices of visiting. At least in the near future, it seems the popular trends will involve leisure time spent closer to home or on longer, slower, more deliberate, and more meaningful trips.

Early evidence suggests that these trends are likely; it also suggests they may be reserved for the wealthiest travelers. It is at this intersection between environmental and social justice that Uustalo's call for stronger intervention from municipalities will be needed; we have already seen glimpses of what a tourism future left to the free market might look like. We cannot rely on a pandemic to change things, but it has given us the breathing space to slow down and ask, in all seriousness, what other alternatives might be possible.

Summary of the fifth research note in this issue:

In the final research note Heli Koskinen brings up the role of tour operators in preventing the spreading of diseases between humans and animals. The COVID-19 pandemic has made the connections between travel and spreading of diseases topical. Koskinen introduces how by different laws the tourism operators in Finland are responsible for communicating information about the possible animal-related diseases and how to prevent these diseases in travel behaviour. However, in practice the tour operators do not inform about the diseases and do not see the responsibility of communicating about the possible diseases as part of a responsible business strategy.

The issue ends with Johan Edelheim's conference greetings from the eleventh Tourism Education Futures Initiative (TEFI) conference, which was held online in June 2020 by the York St John University and the TEFI network. The event was a first online conference organised by the network, and the challenge was how to cherish the core values of these conferences - collective and caring atmosphere - in an online environment. When planning the event, three key elements were considered: everyone should have the possibility to get enough feedback on their presentations, all the presentations should be available also to people not attending the conference, and there should be something physical that connects people. In his greetings, Edelheim describes how the three key elements where achieved and how the conference also enabled longed-for casual meetings and responsible, low-cost conference attendance.

At Sapporo, Taos, Reykjavík and Rovaniemi, 14 December 2020

Johan Edelheim, Jennie Germann Molz, Gunnar Thór Jóhannesson and Outi Rantala

\section{References}

Ulmer, J. B. (2017). Writing slow ontology. Qualitative Inquiry, 23(3), 201-211. https://doi. org/10.1177/1077800416643994 